\title{
Priorities and Motivations of Marine Coastal Restoration Research
}

\author{
Elisa Bayraktarov v,2*, Shantala Brisbane ${ }^{1,3}$, Valerie Hagger ${ }^{4}$, Carter S. Smith ${ }^{5}$, \\ Kerrie A. Wilson ${ }^{6}$, Catherine E. Lovelock ${ }^{4}$, Chris Gillies ${ }^{7,8}$, Andrew D. L. Steven ${ }^{2}$ and \\ Megan I. Saunders ${ }^{2}$ \\ ${ }^{1}$ Centre for Biodiversity and Conservation Science, The University of Queensland, St Lucia, QLD, Australia, ${ }^{2}$ CSIRO Oceans \\ and Atmosphere, Queensland Biosciences Precinct, St Lucia, QLD, Australia, ${ }^{3}$ School of Earth and Environmental Sciences, \\ The University of Queensland, St Lucia, QLD, Australia, ${ }^{4}$ School of Biological Sciences, The University of Queensland, \\ St Lucia, QLD, Australia, ${ }^{5}$ Nicholas School of the Environment, Duke University Marine Lab, Beaufort, NC, United States, \\ ${ }^{6}$ Institute for Future Environments, Queensland University of Technology, Brisbane, QLD, Australia, ${ }^{7}$ The Nature \\ Conservancy, Carlton, VIC, Australia, ${ }^{8}$ TropWATER, James Cook University, Townsville, QLD, Australia
}

OPEN ACCESS

Edited by:

Laura Airoldi,

University of Bologna, Italy

Reviewed by:

Donna Marie Bilkovic

College of William \& Mary,

United States

Bregje Karien van Wesenbeeck,

Deltares, Netherlands

*Correspondence:

Elisa Bayraktarov

e.bayraktarov@uq.edu.au

Specialty section:

This article was submitted to Marine Conservation and

Sustainability,

a section of the journa

Frontiers in Marine Science

Received: 22 March 2020 Accepted: 29 May 2020

Published: 08 July 2020

Citation:

Bayraktarov E, Brisbane S, Hagger V, Smith CS, Wilson KA, Lovelock CE,

Gillies $C$, Steven $A D L$ and

Saunders MI (2020) Priorities and

Motivations of Marine Coastal

Restoration Research.

Front. Mar. Sci. 7:484.

doi: 10.3389/fmars.2020.00484
Active restoration is becoming an increasingly important conservation intervention to counteract the degradation of marine coastal ecosystems. Understanding what has motivated the scientific community to research the restoration of marine coastal ecosystems and how restoration research projects are funded is essential if we want to scale-up restoration interventions to meaningful extents. Here, we systematically review and synthesize data to understand the motivations for research on the restoration of coral reefs, seagrass, mangroves, saltmarsh, and oyster reefs. We base this analysis off a published database of marine restoration studies, originally designed to estimate the cost and feasibility of marine coastal restoration, derived from mostly scientific studies published in peer-reviewed and some gray literature. For the present study, the database was updated with fields aimed at assessing the motivations, outcomes, and funding sources for each project. We classify restoration motivations into five categories: biotic, experimental, idealistic, legislative, and pragmatic. Moreover, we evaluate the variables measured and outcomes reported by the researchers and evaluate whether projects adhered to the Society for Ecological Restoration's (SER) standards for the practice of ecological restoration. The most common motivation of the scientific community to study restoration in marine coastal ecosystems was experimental i.e., to seek experimental data to answer ecological research questions or improve restoration approach, as expected since mostly peer-reviewed literature was evaluated here. There were differences in motivations among the five coastal ecosystems. For instance, biodiversity enhancement was the most common case for a biotic motivation in mangrove restoration projects. The most common metrics evaluated were growth/productivity, survivorship, habitat function, physical attributes, and reproduction. For most ecosystems, ecological outcomes were frequently reported, with socio-economic implications of the restoration rarely mentioned, except for mangroves. Projects were largely funded by governmental 
grants with some investment from private donations, non-governmental organizations, and the involvement of volunteers. Our findings and database provide critical data to align future research of the scientific community with the real social, economic and policy needs required to scale-up marine coastal restoration projects.

Keywords: marine coastal restoration, motivations for ecological restoration, conservation funding, restoration success, restoration metrics, restoration outcome, standards for the practice of ecological restoration

\section{INTRODUCTION}

Despite the goods and services that marine coastal ecosystems provide to humans (UNEP, 2006), ecosystems such as coral reefs, seagrass, mangroves, saltmarsh, and oyster reefs are being lost at alarming rates worldwide mainly due to unsustainable land use, coastal development and climate change (Orth et al., 2000; Valiela et al., 2001; Pandolfi et al., 2003; Duke et al., 2007). Protection alone cannot solve this problem, as many areas have little natural habitat left to conserve, are facing extinction (Aronson and Precht, 2001) or have already become functionally extinct globally (Beck et al., 2011). Ecological restoration or "the process of assisting the recovery of an ecosystem that has been degraded, damaged, or destroyed" (SER, 2004) is urgently needed to assist ecosystems where natural recovery is hindered or impeded (Perrow and Davy, 2002). Ecological restoration principally seeks to recover the functioning of degraded ecosystems, however restoration of marine and coastal habitats can provide a range of ecological and socio-economic benefits, such as coastal protection from flooding and erosion, fisheries habitat, water quality improvements, and carbon sequestration and storage (Duarte et al., 2013; Fodrie et al., 2017; Macreadie et al., 2017; Abrantes et al., 2019; Gilby et al., 2020). The United Nations General Assembly recently declared the "UN Decade on Ecological Restoration" for 2021-2030 and ecological restoration is on the rise as a component of the solution to ameliorate ecosystem degradation (Possingham et al., 2015). For example, the United Nations Sustainable Development Goals call for restoration of marine coastal ecosystems (Goal 14). Marine coastal restoration plays a paramount role in the current focus on nature-based solutions to address global societal challenges (e.g., climate change adaptation and mitigation, supporting fisheries) (Cohen-Shacham et al., 2016) that are presently being advocated across government and industry and will feature as a key topic at upcoming global forums (e.g., UN Oceans Conference, Lisbon in 2020; Post-2020 global biodiversity framework for the UN Convention on Biological Diversity). Despite these high-level goals, a synthetic picture on what motivates people on the ground to undertake restoration in marine coastal ecosystems is lacking.

Restoration is a human undertaking; therefore, it is critical to understand the motivations of individuals and organizations to conduct restoration, and how those motivations relate to project outcomes or funding sources. Understanding motivations, defined as "a reason or reasons for acting or behaving in a particular way" (oxford dictionary), has been well-assessed in various fields of socio-ecological research, for instance, to assess the reasons for people to engage in community-based conservation (Nilsson et al., 2016), to conserve urban biodiversity (Dearborn and Kark, 2010), or to volunteer in marine conservation programs (Kitney et al., 2018). The reasons or motivations why terrestrial ecosystems are restored have been described as "numerous, disparate, generally understated, and commonly underappreciated" (Clewell and Aronson, 2006). Little is known about the motivations of individuals or organizations to undertake restoration in marine and coastal environments. When we understand people's motivations, we can engage them toward achieving common goals. Therefore, understanding the motivations of individuals and organizations to restore are essential to better align these with the desired project outcomes, funding sources, and to overcome the barriers to scaling-up marine coastal restoration practice.

Motivations for a particular restoration project may be complex, as there are likely multiple agents, governance structures, and funding sources involved. For instance, marine coastal restoration projects form part of many government and non-government environmental programs, which are being implemented by a range of stakeholders including community and Indigenous groups, conservation groups, not-for-profit organizations, and private companies. Scaling-up restoration efforts to meet international commitments (UNEP, 2019), necessarily involves a larger number and variety of stakeholders, which requires consideration of multiple motivations (Wyborn et al., 2012; Menz et al., 2013). It also requires stronger government policy, sustained funding, improving the relationships with existing restoration networks and community engagement (Gillies et al., 2015). This is particularly important for designing large-scale restoration programs which are carried out by multiple stakeholders. Recognizing and integrating different motivations in setting restoration goals and evaluating outcomes against these goals, can allow projects to deliver multiple benefits, help resolve stakeholder conflict, and sustain stakeholder commitments to restoration in the long-term (Hagger et al., 2017). Furthermore, customizing incentives to cater for diverse stakeholder motivations can also encourage restoration projects (Jellinek et al., 2019).

Motivations for restoration can be categorized into five broad categories: biotic (motivations aligned with the desire to recover lost aspects of local biodiversity), idealistic (personal and cultural expressions of concern or atonement for environmental degradation, reengagement with nature, and/or spiritual fulfillment), heuristic (attempts to elicit or demonstrate ecological principles and biotic expressions), technocratic (restoration that is conducted by government agencies or other large organizations to satisfy specific institutional missions and mandates) and 
pragmatic (recover or repair ecosystems for their capacity to provide a broad array of natural services and products upon which human economies depend and to counteract extremes in climate caused by ecosystem loss) (Clewell and Aronson, 2006). This framework was applied by Hagger et al. (2017) to evaluate the reasons why people restore terrestrial habitats and how this influences planning and monitoring approaches to achieve desired outcomes. So far, in a marine context, the framework has only been used to understand the reasons of the scientific community to restore coral reefs, which were largely focused on improving the restoration approach and answering questions of ecological concern, i.e., heuristic/experimental motivations (Bayraktarov et al., 2019). Little is known about the reasons of scientists to restore other marine coastal habitats and whether these motivations differ among coral reefs, seagrass, mangroves, saltmarsh, and oyster reefs.

The Society for Ecological Restoration (SER) was founded in 1988 to "advance the science, practice and policy of ecological restoration to sustain biodiversity, improve resilience in a changing climate, and re-establish an ecologically healthy relationship between nature and culture" (SER, 2020) ${ }^{1}$. The International Standards for the Practice of Ecological Restoration (first edition released by SER, 2016) contain a number of best practice guidelines developed over decades of research and practice from well-established restoration of terrestrial habitats, however is aimed to be transferrable to marine and freshwater ecosystems (McDonald et al., 2016). SER have developed many tools to help restoration practitioners track their progress toward a full ecosystem restoration, such as the "recovery wheel" used to assess advancement based on metrics categorized under the attributes: absence of threats; ecosystem function; external exchanges; physical conditions; species composition; and structural diversity (McDonald et al., 2016). In addition to best practices and metrics, the outcomes from a restoration project can be categorized into ecological, social and economic or a combination thereof following the framework by Wortley et al. (2013). For marine coastal restoration, we do not currently know: (1) whether the best practice standards toward a full ecosystem recovery proposed by SER have been applied; (2) which metrics have been measured to assess recovery; and (3) what the intended outcomes for the restoration projects were.

Allocation of funding may be considered a metric of an organization's level of interest in a subject, therefore, assessing funding sources in relation to motivations for marine restoration helps us to discern the motivations of organizations. Reported marine coastal restoration costs range from USD $\$ 9,000 \mathrm{ha}^{-1}$ for mangrove restoration where large contributions of effort by communities and volunteers are common (Bayraktarov et al., 2016a) to USD $\$ 400,000 \mathrm{ha}^{-1}$ for coral reefs which often involve logistical constraints to reach the restoration sites (Bayraktarov et al., 2019). While investment in conservation of biodiversity continues to be limited and is simply not enough to meet global biodiversity targets (James et al., 1999; McCarthy et al., 2012), it has to be carefully evaluated in its effectiveness to actually make a change for biodiversity (Ferraro and Pattanayak, 2006).

\footnotetext{
${ }_{1}^{1}$ Available online at: https://www.ser.org/
}

Information on restoration projects can be obtained from either the scientific process of examining peer-reviewed papers, or through gray literature such as newspaper reports, newsletters, targeted interviews, or government reports. The knowledge from the former source can be accessed through systematic literature review while the latter is more difficult to synthesize. It is not known what the motivations to restore marine coastal ecosystems from either of these sources are and whether they are aligned with the broader needs to reach restoration at scales. These are: to build a business case and awareness that restoration is feasible, develop a policy framework that enables restoration, to build skills and experience in restoration practitioners and to learn from the expertise of terrestrial restoration and adopt best practices (Gillies et al., 2015). Here we focus on the scientific community, their priorities and motivations to restore marine coastal ecosystems.

We systematically review empirical results from the published literature, with the inclusion of some gray literature and personal communications, to elucidate the reasons why (mostly) scientists engage in the field of marine coastal restoration. We specifically answer the questions: (1) what priorities and motivations do scientists have to engage in marine coastal restoration; (2) do motivations to engage vary between different ecosystems; (3) what are the metrics measured and which restoration attributes did they assess; (4) were best practices for ecological restoration applied; and (5) what is the nature of funding to carry out restoration projects? We answer these questions by expanding and updating a global systematic review focused on cost and feasibility assessments of marine coastal restoration (Bayraktarov et al., 2016a), to compare the results across five ecosystems: coral reefs, seagrass, mangroves, saltmarsh and oyster reefs.

\section{METHODS}

This paper assesses the motivations underpinning marine coastal restoration as reported primarily by scientists in peer-reviewed scientific literature. The analysis builds off a published database of 235 papers on marine coastal restoration projects which was developed using search criteria aimed at quantifying the cost and feasibility of marine coastal restoration (Bayraktarov et al., 2016a,b). For the purpose of this study the database was updated with more recent literature and expanded to include information on the motivations, outcomes, and funding sources of the research. We used a modified version of the framework by Clewell and Aronson (2006) as adopted by Bayraktarov et al. (2019) for corals reefs to categorize the motivations of the restoration projects. Coral reef data presented in this paper was previously published (Bayraktarov et al., 2019) and is included here as a comparison to four other ecosystems.

\section{Database}

The database of Bayraktarov et al. (2016a) which included publications up to 2014, was expanded for the present study using the following methods: The database was updated to include publications until 2018. This involved a systematic literature search using Web of Science (Core collection; Thomson Reuters, New York, New York, U.S.A.) and Scopus (Elsevier, Atlanta, 
Georgia, U.S.A.) and the title search terms "(ecosystemA* OR ecosystemB*) AND restor*," as well as "(ecosystemA* OR ecosystemB*) AND rehab*." The terms ecosystemA and ecosystemB were used as placeholders for two different words describing the same ecosystem (e.g., coral and coral reef, mangrove and mangal, saltmarsh and salt marsh, shellfish, and oyster). For consistency with Bayraktarov et al. (2016b), an EndNote (Version X8.1; Thomson Reuters.) search was then performed within the full text using the search terms "(cost* OR feasib* OR surviv*).” Additional information was gathered by following citations, personal communications, and inspecting diverse restoration databases and webpages. Reports included in the database were mostly from the published literature but also included some information from webpages and personal communications. English was the primary language in which the restoration projects were described with a few exceptions in Spanish. The updated database consisted of 275 studies of which $64 \%$ were scientific papers published in journals and $36 \%$ included other reports (e.g., books, book chapters, conference proceedings, reports, webpages, and personal communication).

Data were extracted from each primary study (publications describing original research) where each study described one restoration project. The first observation representing a study in the database was used for analyses. An exception was the study by Edwards and Gomez (2007), which contained information on five independent restoration projects which were sufficiently described to enable data extraction from the same source for multiple projects. Secondary sources, reviews or guideline papers were excluded because these studies usually lack the level of detail required for data extraction to inform motivations, variables measured or restoration outcomes.

For the present study, 275 primary (original research) and secondary (research referring to original research e.g., reviews) restoration studies across the five ecosystems - coral reefs (87), seagrass (57), mangroves (64), saltmarsh (33), and oyster reefs (34) - met the above search criteria. These were further refined to 186 primary studies (75 coral reefs; 30 seagrass; 38 mangrove; 23 saltmarsh; 20 oyster reefs) to determine motivations, variables measured, outcomes reported, funding sources and alignment with the six standards for the practice of ecological restoration described by McDonald et al. (2016) (see methods, below). Projects were carried out in 57 countries (Figure 1), of which 27 had high-income economies, 17 had upper-middle income economies, 10 had lower-middle income economies and two were from countries with a low income economy as defined by The World Bank (2014).

\section{Motivations for Engaging in Marine Coastal Restoration}

For each entry in the database, the motivations of the authors to engage in marine coastal restoration were assigned to five categories adopted from Clewell and Aronson (2006). For example, enhancing or increasing biodiversity is a biotic motivation to restore coral reef habitat and improve resilience to ocean warming and acidification (McLeod et al., 2019). Other examples for biotic motivations are an increase in the number of native species (e.g., for saltmarsh), habitat creation, ecosystem connectivity, and increasing the ecological resilience of the ecosystem (Table S1). Improving the approach to restore coral reefs by harvesting and culturing wild coralspawn slicks to apply at large, industrial scales (Doropoulos et al., 2019) is an experimental (or heuristic) motivation. Building community awareness, involvement, a shared responsibility for the restoration site, and creating jobs through restoration activities is an idealistic motivation for the restoration of coral reefs (Kittinger et al., 2016). Marine ecosystem restoration required to offset biodiversity in order to comply with an environmental policy (Jacob et al., 2018) is a legislative (or technocratic) motivation. The provision of ecosystem services is an important pragmatic motivation worldwide, for example community-based restoration of mangroves in Indonesia for storm protection (Brown et al., 2014), and oyster and coral reef restoration for fisheries production (Gilby et al., 2018).

To identify motivations or reasons for restoration we screened for key words like objective, purpose, goal, success, intent, aim, focus, intention, aspiration, direction, target. Motivations for each marine coastal restoration project were classified as biotic; experimental; idealistic; legislative; and/or pragmatic (see examples for motivations in Table S1) following Clewell and Aronson (2006) and Bayraktarov et al. (2019). These five categories are not necessarily mutually exclusive but comprise a categorization that facilitates their systematic description (Clewell and Aronson, 2006).

\section{Variables Measured}

The methods of each study were inspected to extract variables measured during monitoring of the restoration sites. Variables were grouped to specific "sub-attribute categories" (e.g., survivorship) which were nested within broader "attribute categories" (e.g., ecosystem function) (Table S2) modified from the International Standards for the Practice of Ecological Restoration (McDonald et al., 2016). Following these standards, the variables survival, growth and productivity were categorized under the attribute "ecosystem function." These variables have been categorized as variables measuring the biological response of the ecosystem to the restoration interventions in other studies e.g., Hein et al. (2017).

Variables measured during monitoring of the restoration sites included those related to ecosystem function and processes (e.g., survival, reproduction, growth, and productivity), but also the physical environment of the site (e.g., temperature, turbidity, and $\mathrm{pH}$ ), the level of threats (e.g., invasive species, predators, and physical damage), as well as social and socio-economic variables (Table S2).

\section{Restoration Outcomes}

The type of restoration outcome was described after searching the abstract, results, and discussion of each study. We categorized the reported outcomes of each restoration project as ecological, economic, social, or as a combination thereof following Wortley et al. (2013). 


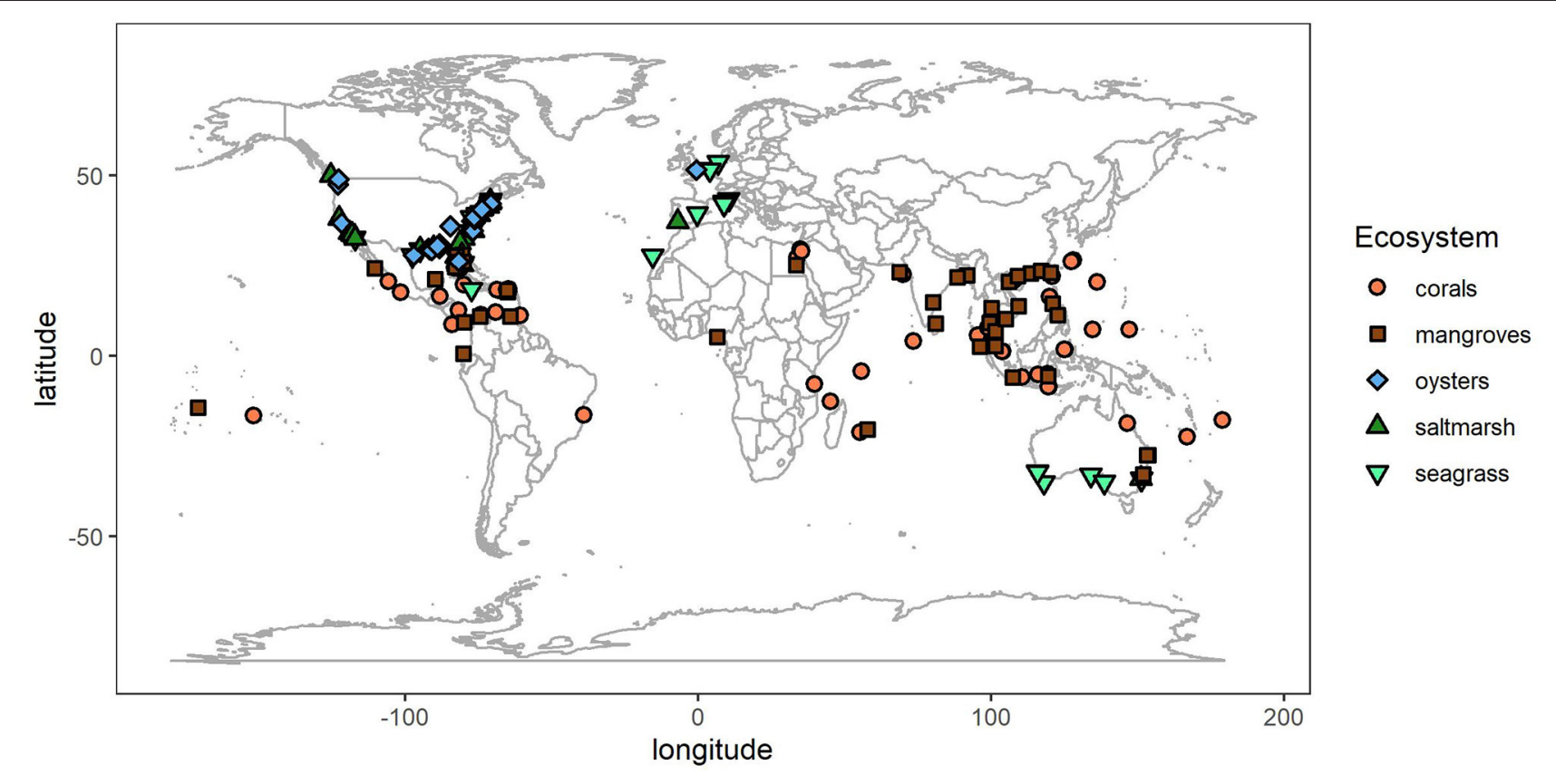

FIGURE 1 | Locations of all marine coastal restoration projects in the database.

\section{Standards for Ecological Restoration}

Each project was searched for whether it aligned (fully or partially) with any or all of the six standards for the practice of ecological restoration (McDonald et al., 2016). We modified the six standards for practical reasons to: (1) having a reference ecosystem to compare restoration progress against a reference; (2a) having clear targets and goals, as well as SMART (specific, measurable, adequate, repeatable, and time-bound) restoration objectives; (2b) having specific and measurable indicators to evaluate targets, goals, and objectives; (2c) employing adaptive management of the restoration site; (3) assessing the capacity for natural recovery of the ecosystem prior to restoration intervention; (4) aiming for full ecosystem recovery; (5) drawing from all relevant knowledge including science, practice and traditional knowledge; and (6) having early and ongoing stakeholder engagement with communities and end-users. Active adaptive management incorporates uncertainty and the process of iterative learning about the system being managed, which leads to better decisions (McCarthy and Possingham, 2007). We added the adaptive management component to complement the SER standards which did not include this principle. Because of the differences in time periods between SER standards (2016) and studies assessed (1974-2018), we did not search for wording of the six standards verbatim but the "philosophy" or scientific "intent" behind them. A full list of all categories and extraction rules are included in the (Table S3). Primary studies were categorized into whether they addressed each of the standards by SER, only addressed them partially and whether they have not addressed them at all. "Partially" often means that a certain component was missing in order to fully address the specific standard. For instance, studies that only partially addressed the standard of "having clear targets and goals, as well as SMART restoration objectives" often had clear restoration objectives, but those objectives were not time-bound.

\section{Financial Contributors of Marine Coastal Restoration Projects}

Following the methods by Bakker et al. (2010), we extracted data from the acknowledgments section of each primary study and identified the funding sources as a combination of: (1) government funding, (2) non-government funding, (3) private investments by businesses, individuals or philanthropy, and (4) projects supported by volunteer labor.

\section{RESULTS}

\section{Motivations of Scientists to Engage in Marine Coastal Restoration}

The most common primary motivation to engage in restoration across all five ecosystems was experimental i.e., to further ecological knowledge and improve restoration techniques. Sixtyseven percent (50 studies out of 75) of the primary studies investigating coral reef restoration followed this rationale with $63 \%$ for seagrass (19 out of 30 studies), $24 \%$ for mangroves (9 out of 38 studies), $48 \%$ for saltmarsh (11 out of 23 studies), and $85 \%$ for oyster reefs (17 out of 20 studies) (Figure S1a). The second most predominant motivations were biotic, i.e., to enhance biodiversity, and legislative, i.e., to restore the ecosystem after environmental impact such as ship grounding or oil spill as well as for biodiversity offsets. Only a small number of studies followed the pragmatic motivation to enhance ecosystem services. Six mangrove studies were motivated by enhancing coastal protection through restoration, while three studies on 

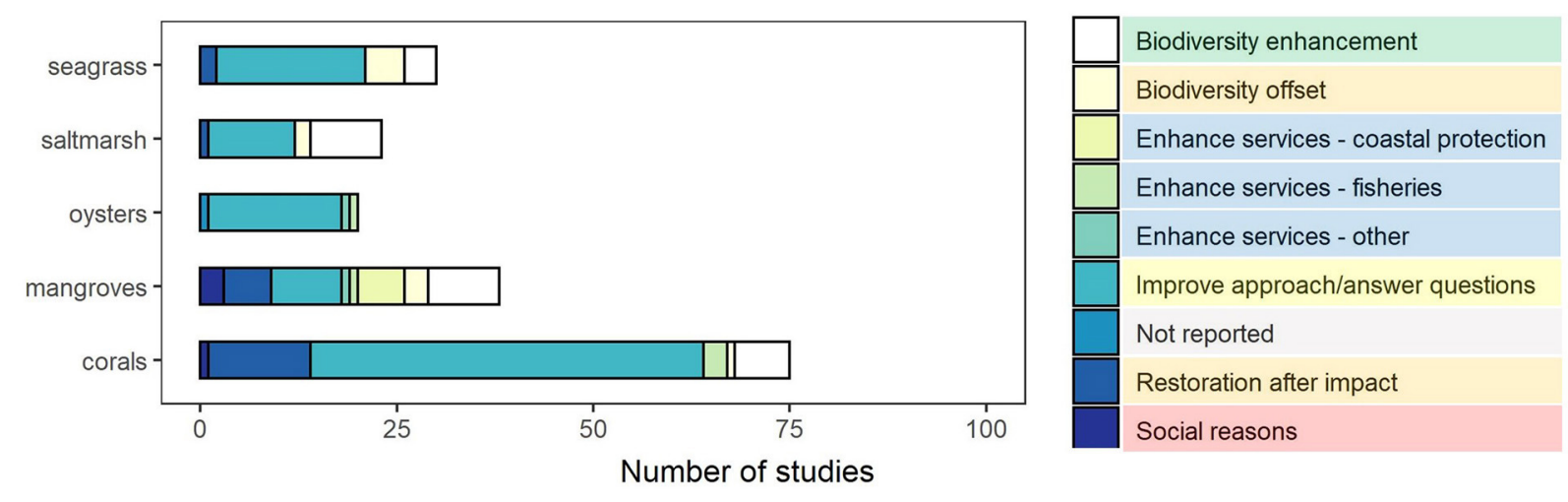

Motivations categories

$\square$ biotic

experimental

$\square$ idealistic

$\square$ legislative

$\square$ pragmatic

none

FIGURE 2 | Primary motivation for marine coastal restoration aggregated by ecosystems for restoration studies. The total number of primary studies: $n=186$. The motivation categories biotic, experimental, idealistic, legislative, and pragmatic are color coded.

coral reefs, one oyster reef restoration study and one mangrove study aimed to increase fisheries production from restoration.

Primary motivations varied among ecosystems, with the most common motivations in mangrove projects being biotic (i.e., biodiversity enhancement) while in oyster, coral, saltmarsh and seagrass studies, projects were most often motivated by the experimental rationale (i.e., improving restoration approaches, technology and methods and answering ecological research questions) (Figure 2). Restoration projects of coral reefs had the largest proportion of studies with experimental motivations. Projects for oyster reefs were the only projects that did not include biotic motivations. These were largely motivated by the experimental rationale, as well as pragmatic (e.g., ecosystem services), and to a lesser degree idealistic (e.g., social) reasons. Note that only the primary motivations are described here, while also information on secondary and tertiary motivations are available in the database as well as an analysis in (Figure S1).

\section{Alignment With Standards for Ecological Restoration}

We identified a mismatch between the six standards proposed by McDonald et al. (2016) and the characteristics of the projects, implemented between 1974 and 2018. None of the projects (which were implemented between 1974 and 2018) aligned with all six standards proposed by McDonald et al. (2016). Only the standards of having a reference site; clear, SMART targets and goals; and specific and measurable indicators to track progress were recorded in the studies (Figure 3).

\section{Variables Measured}

The most common attribute category of variables measured was "ecosystem function" (Figure 4), which mostly described the sub-categories growth/productivity (assessed 387 times); survivorship (151 times); habitat function (130 times); but also physical attributes (79 times); and reproduction (75 times) were often assessed (Table 1).

\section{Restoration Outcome}

Ecological outcomes were the most commonly reported outcomes (79.0\% of all primary studies, Figure 5). Some studies reported an ecological and social outcome (10.2\%). Only $2.2 \%$ of the overall studies reported a combined ecological, social and economic outcome. Mangrove ecosystems were the only ecosystem for which all types of outcomes i.e., ecological, social and economic as well as combinations thereof were reported. Studies of the other ecosystems reported predominantly ecological outcomes; seagrass (93.3\%), saltmarsh (91.4\%), oyster reefs $(85.0 \%)$, and coral reefs $(77.3 \%)$ (Table 2$)$.

\section{Financial Contributors}

Restoration projects were primarily funded by government agencies (92 of 186 studies) or government agencies in combination with other funding institutions (149 studies). Few studies were funded exclusively by non-government organizations (NGO) (four studies) or private organizations (10 studies), and no studies were supported exclusively through volunteer effort. Sixty-four studies reported multiple funding types and 16 studies did not acknowledge any funding (Figure 6A). Government funding was the largest contributor to restoration for each individual ecosystem, funding $83 \%$ of coral projects (62 of 75 studies), $82 \%$ of mangrove projects (31 of 38 studies), $90 \%$ of oyster projects (18 of 20 studies), $78 \%$ of saltmarsh projects (18 of 23 studies), and $67 \%$ of seagrass projects (20 of 30 studies). Coral reef restoration projects also had a large contribution of funding by NGOs (19 studies) and by donations and investments from private businesses (15 studies). The investment by NGOs vs. unpaid volunteers was equivalent for mangrove restoration projects (11 studies each). For oyster reef restoration projects volunteer-funded projects (11 studies) exceeded NGO (eight studies), and private funding (five studies). Saltmarsh and seagrass had only a few NGO and volunteer-based projects. Seagrass had a relatively small proportion of investment by private donations or businesses (seven studies) (Figure 6B). 


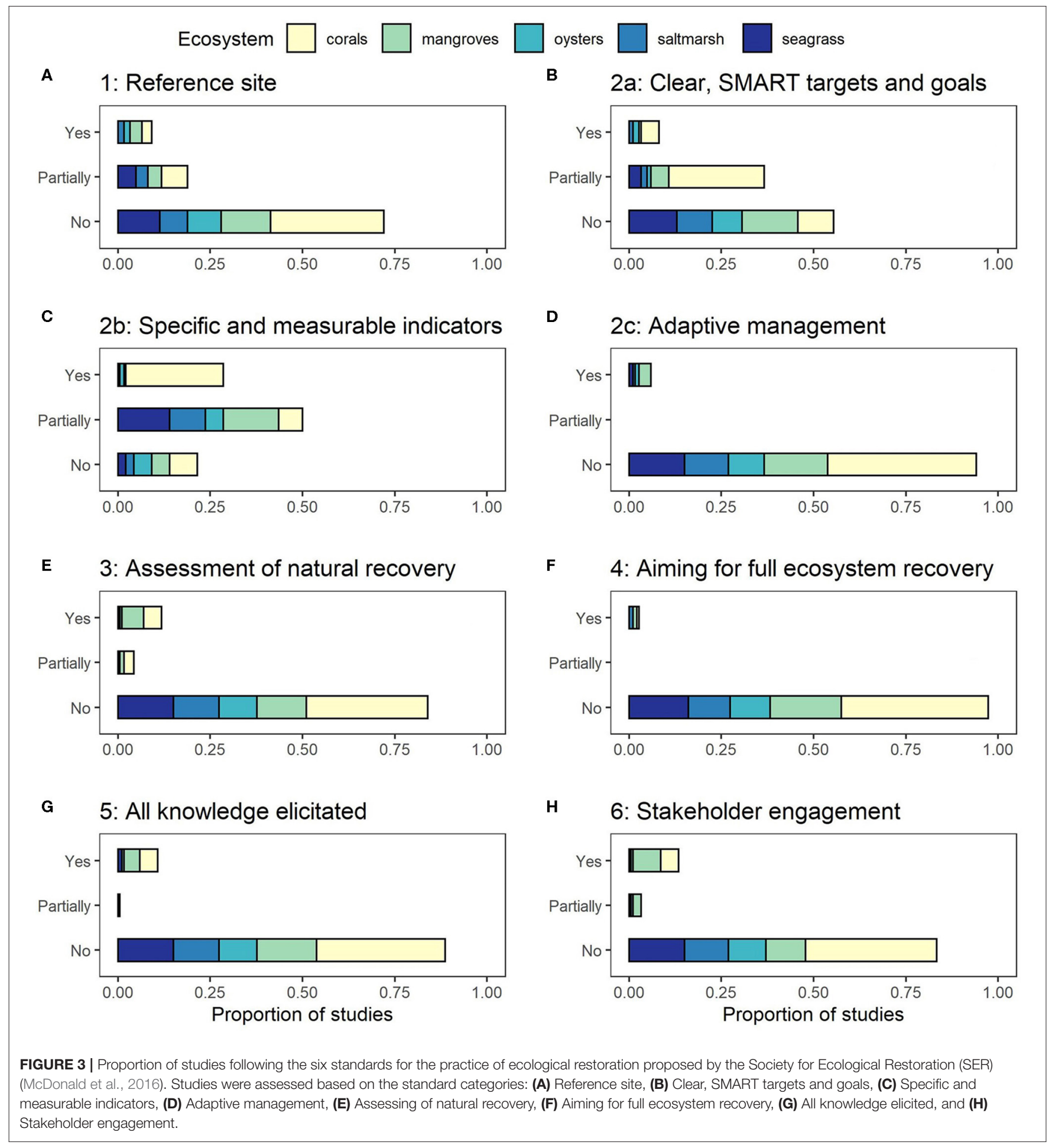

\section{DISCUSSION}

Based on a published database of primarily published literature, we found that scientists who engaged in marine coastal restoration globally were mainly motivated by experimental reasons i.e., to improve the restoration approach and/or answer ecological questions. This differs from the survey results obtained from terrestrial restoration practitioners across Australia, who were mainly motivated by biodiversity enhancement and also biodiversity offsetting, water quality improvements, and social reasons (Hagger et al., 2017). It is yet to be explored whether surveying marine coastal practitioners would lead to similar results. Our results based on the scientific literature may reflect a lag in development of the field, where restoration 


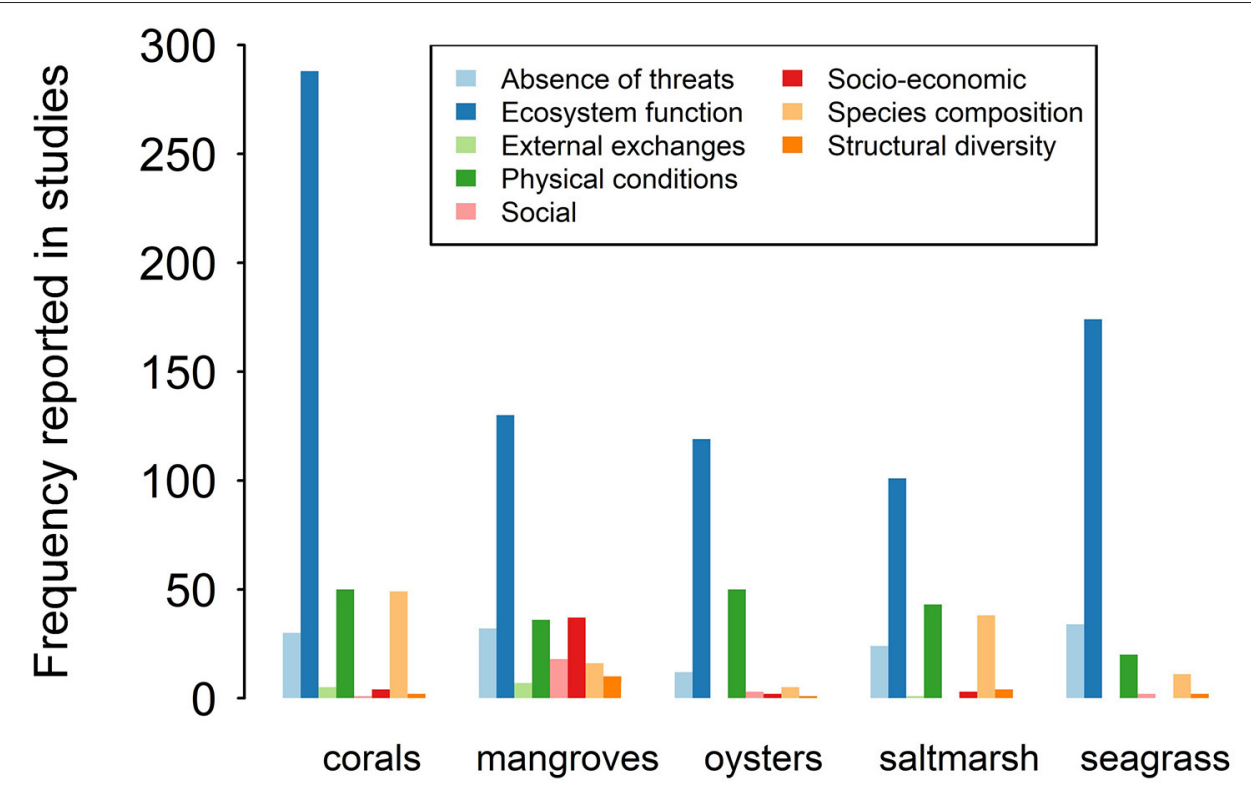

FIGURE 4 | Attribute categories of the variables measured to assess the restoration studies.

approaches for coral, kelp and seagrass in particular are still in the proof-of-concept phase, focused at small-scale experimental interventions (Bayraktarov et al., 2016a) and not yet (widely) aiming to maximize biodiversity or the provision of ecosystem services. This finding might also be biased by the difference in motivation of those who do research with publication as a key motivation (i.e., scientists and students), vs. those involved in the practice and operationalization of large-scale restoration projects (NGOs, natural resource management bodies, community groups, governments, consultants, developers etc.). For example, a study that used a systematic review to assess the global literature of marine coastal restoration found that ca. $84 \%$ of published studies included an author affiliated with a university (Zhang et al., 2018).

It is also questionable whether restoration for the purpose of methodology development should be considered "restoration" sensu stricto as per definition of the Society for Ecological Restoration (SER). Projects aiming at an improvement of the restoration approach are typically carried out at small scales (Bayraktarov et al., 2016a) and do not aim to achieve a full ecosystem recovery (this study). We observed that restoration of coral reefs in low income and lower-middle income countries followed the experimental rationale, however, this was only the case for seven studies on mangrove restoration. In countries with low and lower-middle income economies, mangrove restoration was motivated by pragmatic, biotic, social and legislative reasons, potentially due to the growing interest in carbon storage, livelihood creation and nature-based solutions (Grabowski and Peterson, 2007; Greiner et al., 2013; Cohen-Shacham et al., 2016; Macreadie et al., 2017). All records on the restoration of seagrass, saltmarsh and oyster reefs in our database were from countries with a high or upper-middle income economy and cases from countries with low and lower-middle income economies remain unknown to the published literature.

Motivations of scientists to engage in marine coastal restoration vary among ecosystems. While the restoration of most ecosystems described here were motivated by an experimental rationale, mangrove restoration differed in that projects were equally motivated by biotic, experimental, and pragmatic rationales. Mangrove restoration projects also deviated in the type of outcomes reported. While projects for most ecosystems reported a purely ecological outcome, mangrove restoration research often considered socio-economic implications of the restoration intervention and had the highest proportion of social and socio-economic variables included as metrics of achieving outcomes. Many of the published studies recommended greater efforts to incorporate social, economic, and cultural factors in assessing the effectiveness of ecological restoration e.g., Ruiz-Jaen and Mitchell Aide (2005), indicating that this is a priority for future marine restoration practice. Restoration of mangroves is less expensive, has been accomplished over larger areas, and it has higher survival of restored organisms than the other coastal ecosystems (Bayraktarov et al., 2016a). Failures of mangrove restoration have occurred, but this has been largely associated with poor site selection, often driven by social factors (Lee et al., 2019). The feasibility of mangrove restoration may be due to being practiced for a relatively long duration (since at least 1977, with reforestation of mangroves dating back to the early 1900s, Primavera and Esteban, 2008) and has efficient methods, while restoration of other marine coastal ecosystems may need to mature. The maturity of mangrove restoration was evident in the reduced focus on improving methods compared to the other ecosystems. There also 
TABLE 1 | Number of primary restoration projects reporting on variables grouped under the following sub-attribute categories.

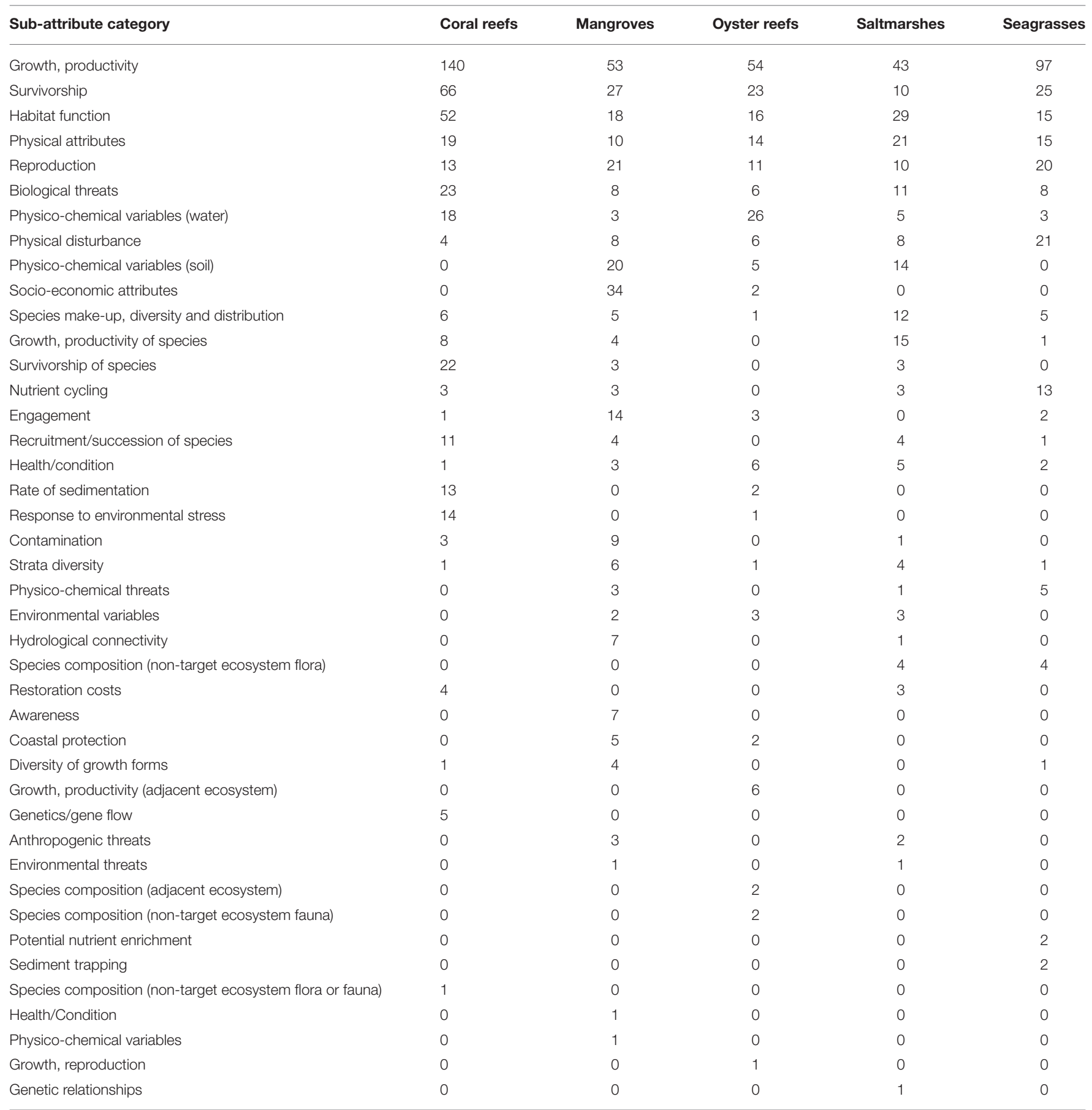

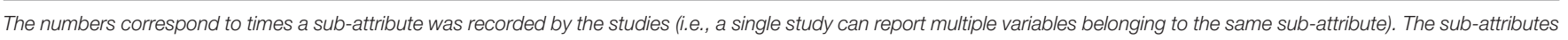
are ordered from most frequently recorded to least frequently recorded across all five ecosystems.

tended to be higher levels of involvement of communities and support by volunteer labor in mangrove restoration (Brown et al., 2014) which may also contribute to successful projects at larger spatial scales. Greater accessibility to the restoration sites by communities may also contribute to enhanced success of mangrove restoration which can be carried out by fishermen and small boats, in comparison to ecosystems like coral reefs, oyster reefs and seagrass which require underwater activities and other logistics (e.g., divers, SCUBA equipment).

This analysis included three main biases inherent in the database: (1) a large number of papers in the field of research 


\section{$79.0 \% \quad 10.2 \% \quad 0.5 \%$ Ecological Social}

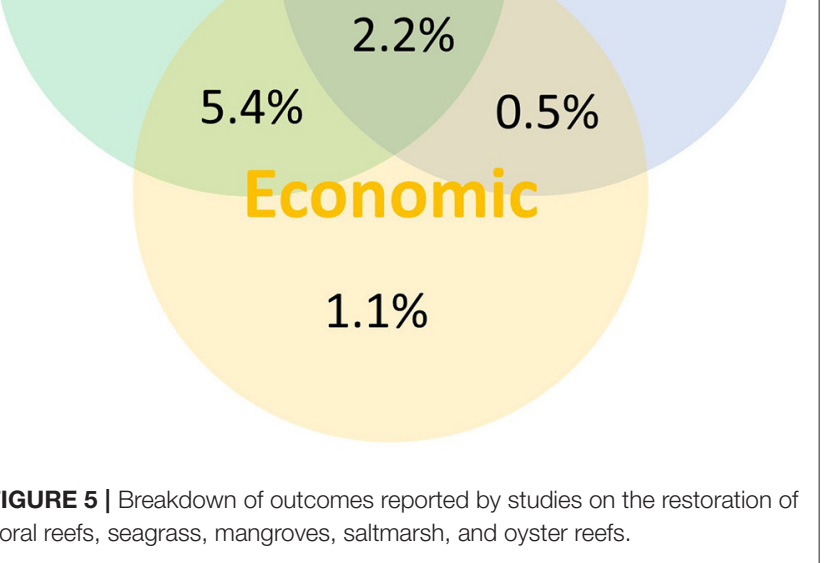

of marine coastal restoration are omitted due to a relatively narrow scope provided by the original search terms ("cost," "feasibility," and or "survival"); (2) much of the knowledge from practitioners who conduct restoration, and whom have less incentive to publish in the literature, are omitted; (3) the database is comprised of records mainly in English and a few entries in Spanish. Despite these limitations, the analysis is systematic and repeatable, and the biases are consistent across the five ecosystems. Therefore, while the results may not paint a complete picture of the motivations for marine ecological restoration in general, and do not canvass the full body of literature in the field, the results can be used to compare general trends for scientists studying restoration across the five coastal ecosystems. A more comprehensive search that goes beyond the publication bias, capturing newspaper articles, newsletters, social media posts, blogs, YouTube videos, and incorporates targeted interviews with marine coastal restoration practitioners may yield different results because it would represent the motivations of the wider restoration community.

The focus of restoration on experimental motivations may not be surprising when data are assessed from the published scientific literature. Many restoration practitioners may not publish results because of limited resources, and thus their motivations for restoration may differ from what we have found in our assessment of the scientific literature. This is a general trend in conservation where there is still a gap between conservation science and practice (Sunderland et al., 2009; Milner-Gulland et al., 2010). Studies where motivations were gleaned by surveying restoration practitioners have found primarily biotic, pragmatic or social rationales for restoration, e.g., Bernhardt et al. (2007) and Hagger et al. (2017). Information on large-scale restoration and in countries where English is not the main language is often not published, with only few exceptions, e.g., Bayraktarov et al. (2020), and we may be missing out on more than $35 \%$ of the knowledge in conservation if peer-reviewed literature searches are restricted to English (Amano et al., 2016). Another caveat is that funding provided by the research institution in terms of salaries and facilities are rarely acknowledged in a scientific publication. The results presented here may largely ignore the contributions of academic institutions and academics who often volunteer their time to carry out the research.

The most common metrics recorded in marine coastal restoration research were growth/productivity, survivorship, habitat function, physical attributes and reproduction. This is in line with plant survival being the most commonly used metric in terrestrial restoration practice, followed by absence of weeds or pest animals, plant species diversity, and vegetation cover (Hagger et al., 2017). Assessments based on peerreviewed literature show that restoration progress is commonly reported by variables related to biodiversity, vegetation structure or ecological functions (Ruiz-Jaen and Mitchell Aide, 2005; Basconi et al., 2020). Expanding the variables monitored in marine coastal restoration (e.g., monitoring ecosystem function or ecosystem services more effectively than simply assessing growth/productivity and survival) is an important step toward capturing socio-economic outcomes, to improve the effectiveness of restoration and alignment with the motivations of stakeholders sectors such as fishing, aquaculture, governments, tourism and water utilities/managers (Fonseca et al., 2000; Paling et al., 2009; Basconi et al., 2020).

Restoration projects presented here were primarily funded by government agencies, either alone or in combination with other funding contributors. Restoration forms part of many government and non-government environmental programs, and is implemented by a diverse range of stakeholders, from community groups and not-for-profit organizations, to private companies and government agencies (Hobbs, 2017; Maron and Louis, 2018). Increased diversification of financing will be required to enable wider adoption and scaling-up of marine coastal restoration, to meet ambitious recent targets (e.g., increasing the global mangrove area by $20 \%$ by 2030 within the 'Global Mangrove Alliance' - a coalition of global conservation organizations Waltham et al., 2020). Opportunities such as market-based mechanisms to fund marine coastal restoration, including payment for ecosystem services (e.g., carbon storage or nutrient cycling) may increase resources available for restoration (Basconi et al., 2020). Additionally, a combination of government funding in conjunction with supportive policy has been found to leverage substantial private funding for large-scale marine coastal restoration in the USA, an approach which could be more widely implemented (Waltham et al., 2020). For example, the "Mangroves for the Future" program, established under the International Union for the Conservation of Nature (IUCN) and the United Nations Development Program, and involving many institutional partners, have promoted large-scale planting of mangroves throughout Southeast and South Asia.

Most of the projects we assessed did not address the six key standards of the International Standards for the Practice 
TABLE 2 | Percentage of outcome categories reported.

\begin{tabular}{|c|c|c|c|c|c|}
\hline Outcome & Coral reefs & Seagrass & Mangroves & Saltmarsh & Oyster reefs \\
\hline Ecological & 77.3 & 93.3 & 60.5 & 91.4 & 85.0 \\
\hline Social & 0 & 0 & 2.6 & 0 & 0 \\
\hline Ecological \& social & 13.3 & 6.7 & 15.8 & 0 & 5.0 \\
\hline Ecological \& economic & 8.1 & 0 & 5.3 & 4.3 & 5.0 \\
\hline None & 0 & 0 & 0 & 4.3 & 5.0 \\
\hline
\end{tabular}

The number of studies used for analysis was $n=75$ for coral reefs, $n=30$ for seagrass, $n=38$ for mangroves, $n=23$ for saltmarsh and $n=20$ for oyster reefs.

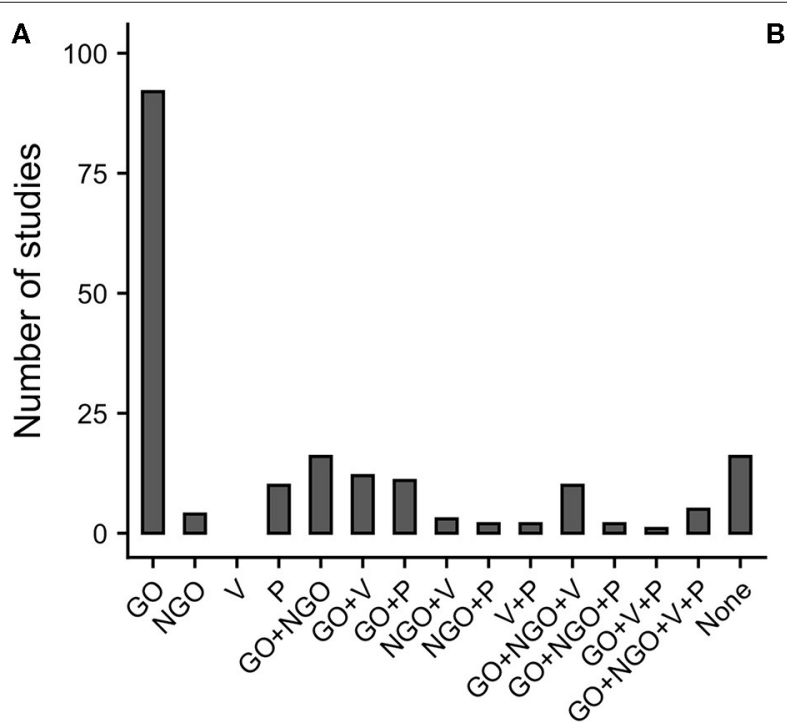

Funding types

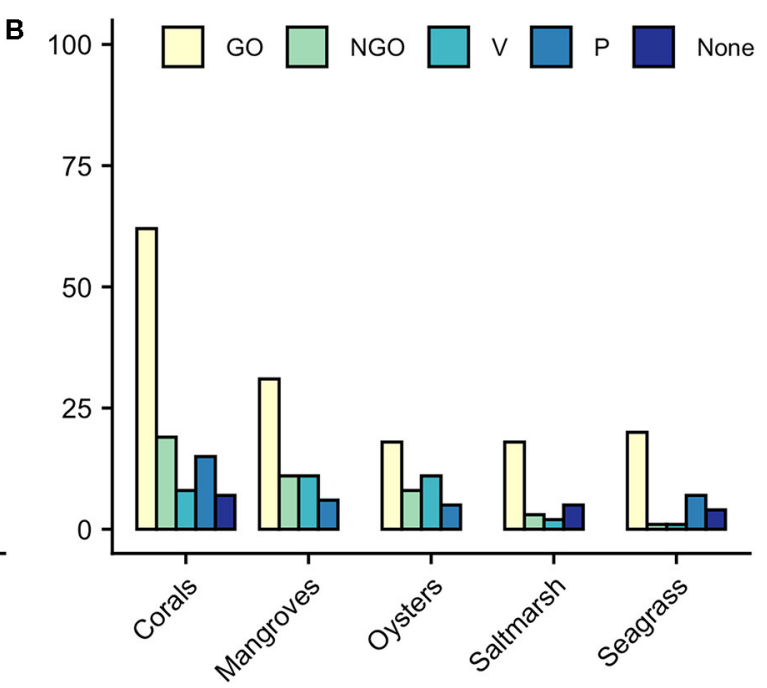

Ecosystem

FIGURE 6 | Type of financial contributors to marine coastal restoration projects extracted from the acknowledgments of each primary study. (A) Shows the combination of funders across all studies $(n=186)$. (B) Shows the number of studies by ecosystem that had support from each funding type (note: a single study can be represented in multiple bars if it received funding from multiple sources). Abbreviations: GO, governmental; NGO, non-governmental; V, supported by volunteers; P, supported by private organizations or businesses, and None, no funding reported.

of Ecological Restoration by McDonald et al. (2016). This is not necessarily surprising, given that the standards were first released in late 2016, while the restoration projects described here were implemented between 1974 and 2018, and that two thirds of the studies were motivated by experimental reasons. The earliest studies in our database were published in 1974 by seagrass, followed by 1977 for mangroves, 1988 for saltmarsh, 1991 for coral reefs and 1999 for oyster reefs. While the limited number of projects and studies prevented us from assessing changes in adoption of the SER concepts embedded in projects over time, our study provides a baseline assessment from which future studies can assess changes in the application of best practices in restoration projects, which are key to scaling-up restoration of marine coastal ecosystems and achieving economies of scale (Gillies et al., 2015; Bayraktarov et al., 2016a; McDonald et al., 2016; van Katwijk et al.,
2016). Nevertheless, it should be noted that there are other, equally valuable reasons for restoring marine and coastal habitat that go beyond SER's goal of reaching full ecosystem restoration, which may expand future restoration initiatives. Examples include restoration for socioeconomic and cultural benefits (Kittinger et al., 2016), building/engineering with nature for green infrastructure and urbanization control (VargasHernández and Zdunek-Wielgołaska, 2020) or to explore the value of reconstructed novel ecosystems (Hobbs et al., 2006) as nature-based solutions for climate change mitigation and adaptation (e.g., for costal protection, Reguero et al., 2018).

The hurdles that many marine coastal restoration practitioners experience are typically not related to the restoration approach or technique but rather deal with finding agreements between the different stakeholders involved, having a policy framework which allows for the implementation of the 
restoration projects, a clear legislation related to biodiversity offsets, and competition between different organization carrying out restoration (Menz et al., 2013; Gillies et al., 2015; Waltham et al., 2020; Stewart-Sinclair et al. submitted). To increase access to information on practitioner-led restoration activities and showcase how barriers to marine coastal restoration can be overcome, we recommend that practitioners connect with existing coastal ecosystem networks, such as the Global Mangrove Alliance or Seagrass Watch, and encourage data sharing (Worthington et al., 2020). Better guidance for data gathering and monitoring would assist in disseminating information and evaluating outcomes to support future funding.

\section{CONCLUSION}

Our work based on systematic literature review suggests that the restoration of marine coastal ecosystems is a developing field of conservation, with the scientific community still largely motivated by evaluation of experimental approaches. While the restoration of some ecosystems (e.g., coral reefs, seagrass, saltmarsh, and oyster reefs) may still be in a rapidly developing proof-of-concept phase, the scientific community carrying out mangrove restoration has begun to be motivated by, and engage in, a broader consideration of socio-economic and other benefits, similar to motivations reported for restoration of terrestrial ecosystems. We found that government funding supports most projects with matching involvement from a range of other sectors. Increased involvement from other sectors could increase resources available for marine and coastal restoration which may push restoration science along a developing trajectory beyond small-scale experimental studies. We show that marine coastal restoration research is still much focused on experimental work, while it requires a better alignment with the real needs for scaling-up future efforts such as counteracting the biodiversity decline, solving issues around biodiversity offset policy, reaching resilience goals by providing ecosystems services for climate change adaptation and mitigation to humans, and achieving community acceptance and participation. More science on the socio-economic benefits from restoring marine coastal

\section{REFERENCES}

Abrantes, K. G., Sheaves, M., and Fries, J. (2019). Estimating the value of tropical coastal wetland habitats to fisheries: caveats and assumptions. PLOS ONE 14:e0215350. doi: 10.1371/journal.pone.0215350

Amano, T., González-Varo, J. P., and Sutherland, W. J. (2016). Languages are still a major barrier to global science. PLoS. Biol. 14:e2000933. doi: 10.1371/journal.pbio.2000933

Aronson, R. B., and Precht, W. F. (2001). White-band disease and the changing face of Caribbean coral reefs. Hydrobiologia 460, 25-38. doi: 10.1023/A:1013103928980

Bakker, V. J., Baum, J. K., Brodie, J. F., Salomon, A. K., Dickson, B. G., Gibbs, H. $\mathrm{K}$., et al. (2010). The changing landscape of conservation science funding in the United States. Conserv. Lett. 3, 435-444. doi: 10.1111/j.1755-263X.2010.00125.x

Basconi, L., Cadier, C., and Guerrero-Limon, G. (2020). "Challenges in marine restoration ecology: how techniques, assessment metrics, and ecosystem valuation can lead to improved restoration success," in: YOUMARES 9 - The Oceans: Our Research, Our Future. Proceedings of the 2018 conference for Young ecosystems is needed to be able to connect restoration research to policy and people.

\section{DATA AVAILABILITY STATEMENT}

The datasets generated for this study can be found in the Dryad Digital Repository: https://datadryad.org/stash/share/ MKbsS4eQh7w5RjXK4_wXZJawc-gAvdA_FhGvJk0VlPE.

\section{AUTHOR CONTRIBUTIONS}

$\mathrm{EB}, \mathrm{SB}, \mathrm{VH}$, and $\mathrm{KW}$ conceived and designed the research. $\mathrm{EB}$ and $\mathrm{SB}$ carried out data extraction from the published literature. EB, CS, and $\mathrm{VH}$ analyzed the data. EB, SB, VH, CS, $\mathrm{CL}, \mathrm{KW}, \mathrm{CG}, \mathrm{AS}$, and MS wrote and edited the manuscript. All authors contributed to the article and approved the submitted version.

\section{FUNDING}

This work was supported by The Commonwealth Scientific and Industrial Research Organization in Australia. A part of this research was funded by the Australian Research Council (ARC) Center of Excellence for Environmental Decisions and a Future Fellowship awarded to KW. VH was funded by an ARC Linkage grant LP170101171.

\section{ACKNOWLEDGMENTS}

We acknowledge Phoebe J. Stewart-Sinclair and Keila Stark for data extraction support from the published literature and Audrey Van Herwaarden for economic conversions of cost data in the database.

\section{SUPPLEMENTARY MATERIAL}

The Supplementary Material for this article can be found online at: https://www.frontiersin.org/articles/10.3389/fmars. 2020.00484/full\#supplementary-material
Marine Researcher in Oldenburg, eds S. Jungblut, V. Liebich, and M. BodeDalby. (Germany: Springer Switzerland). doi: 10.1007/978-3-030-20389-4_5

Bayraktarov, E., Banaszak, A., Montoya Maya, P., Kleypas, J., Arias-González, J., Blanco, M., et al. (2020). Coral reef restoration efforts in Latin American countries and territories. bioRxiv. doi: 10.1101/2020.02.16.950998v1

Bayraktarov, E., Saunders, M., Abdullah, S., Mills, M., Beher, J., Possingham, H., et al. (2016b). Data From: The Cost and Feasibility of Marine Coastal Restoration. Dryad Digital Repository. doi: 10.1890/15-1077.1

Bayraktarov, E., Saunders, M. I., Abdullah, S., Mills, M., Beher, J., Possingham, H. P., et al. (2016a). The cost and feasibility of marine coastal restoration. Ecol. Appl. 26, 1055-1074. doi: 10.1890/15-1077

Bayraktarov, E., Stewart-Sinclair, P. J., Brisbane, S., Bostrom-Einarsson, L., Saunders, M. I., Lovelock, C. E., et al. (2019). Motivations, success, and cost of coral reef restoration. Restor. Ecol. 27, 981-991. doi: 10.1111/rec.12977

Beck, M. W., Brumbaugh, R. D., Airoldi, L., Carranza, A., Coen, L. D., Crawford, C., et al. (2011). Oyster reefs at risk and recommendations for conservation, restoration, and management. Bioscience 61, 107-116. doi: 10.1525/bio.2011.61.2.5 
Bernhardt, E. S., Sudduth, E. B., Palmer, M. A., Allan, J. D., Meyer, J. L., Alexander, G., et al. (2007). Restoring rivers one reach at a time: results from a survey of US River restoration practitioners. Restor. Ecol. 15, 482-493. doi: 10.1111/j.1526-100X.2007.00244.x

Brown, B., Fadillah, R., Nurdin, Y., Soulsby, I., and Ahmad, R. (2014). CASE STUDY: Community based ecological mangrove rehabilitation (CBEMR) in Indonesia from small (12-33 ha) to medium scales (400 ha) with pathways for adoption at larger scales (> $5000 \mathrm{ha}$ ). Sapiens: Large-scale restoration 7(2). Available online at: https://journals.openedition.org/sapiens/1589

Clewell, A. F., and Aronson, J. (2006). Motivations for the restoration of ecosystems. Conserv. Biol. 20, 420-428. doi: 10.1111/j.1523-1739.2006.00340.x

Cohen-Shacham, E., Walters, G., Janzen, C., and Maginnis, S. (eds.). (2016). Nature-Based Solutions to Address Global Societal Challenges. Gland: IUCN, 97.

Dearborn, D. C., and Kark, S. (2010). Motivations for conserving urban biodiversity. Conserv. Biol. 24, 432-440. doi: 10.1111/j.1523-1739.2009.01328.x

Doropoulos, C., Vons, F., Elzinga, J., ter Hofstede, R., Salee, K., van Koningsveld, M., et al. (2019). Testing industrial-scale coral restoration techniques: Harvesting and culturing wild coral-spawn slicks. Front. Marine Sci. 6:658. doi: $10.3389 /$ fmars.2019.00658

Duarte, C. M., Sintes, T., and Marbà, N. (2013). Assessing the $\mathrm{CO}_{2}$ capture potential of seagrass restoration projects. J. Appl. Ecol. 50, 1341-1349. doi: $10.1111 / 1365-2664.12155$

Duke, N. C., Meynecke, J. O., Dittmann, S., Ellison, A. M., Anger, K., Berger, U., et al. (2007). A world without mangroves? Science 317:41. doi: $10.1126 /$ science.317.5834.41b

Edwards, A., and Gomez, E. D. (2007). Reef Restoration Concepts and Guidelines: Making Sensible Management Choices in the Face of Uncertainty. Coral Reef Targeted Research \& Capacity Building for Management Programme. St Lucia, 38.

Ferraro, P. J., and Pattanayak, S. K. (2006). Money for nothing? A call for empirical evaluation of biodiversity conservation investments. PLoS. Biol. 4:e105. doi: 10.1371/journal.pbio.0040105

Fodrie, F. J., Rodriguez, A. B., Gittman, R. K., Grabowski, J. H., Lindquist, N. L., Peterson, C. H., et al. (2017). Oyster reefs as carbon sources and sinks. Proc. $R$ Soc. B: Biol. Sci. 284:20170891. doi: 10.1098/rspb.2017.0891

Fonseca, M. S., Julius, B. E., and Kenworthy, W. J. (2000). Integrating biology and economics in seagrass restoration: how much is enough and why? Ecol. Eng. 15, 227-237. doi: 10.1016/S0925-8574(00)00078-1

Gilby, B. L., Olds, A. D., Duncan, C. K., Ortodossi, N. L., Henderson, C. J., and Schlacher, T. A. (2020). Identifying restoration hotspots that deliver multiple ecological benefits. Restor. Ecol. 28, 222-232. doi: 10.1111/rec.13046

Gilby, B. L., Olds, A. D., Peterson, C. H., Connolly, R. M., Voss, C. M., Bishop, M. J., et al. (2018). Maximizing the benefits of oyster reef restoration for finfish and their fisheries. Fish Fish. 19, 931-947. doi: 10.1111/faf.12301

Gillies, C. L., Fitzsimons, J. A., Branigan, S., Hale, L., Hancock, B., Creighton, C., et al. (2015). Scaling-up marine restoration efforts in Australia. Ecol. Manage. Restor. 16, 84-85. doi: 10.1111/emr.12159

Grabowski, J. H., and Peterson, C. H. (2007). 15 - restoring oyster reefs to recover ecosystem services. Theor. Ecol. Ser. 4, 281-298. doi: 10.1016/S1875-306X(07)80017-7

Greiner, J. T., McGlathery, K. J., Gunnell, J., and McKee, B. A. (2013). Seagrass restoration enhances "Blue Carbon" sequestration in coastal waters. PLoS One 8:e72469. doi: 10.1371/journal.pone.0072469

Hagger, V., Dwyer, J., and Wilson, K. (2017). What motivates ecological restoration? Restor. Ecol. 25, 832-843. doi: 10.1111/rec.12503

Hein, M. Y., Willis, B. L., Beeden, R., and Birtles, A. (2017). The need for broader ecological and socioeconomic tools to evaluate the effectiveness of coral restoration programs. Restor. Ecol. 25, 873-883. doi: 10.1111/rec. 12580

Hobbs, R. J. (2017). Where to from here? Challenges for restoration and revegetation in a fast-changing world. Rangeland J. 39, 563-566. doi: $10.1071 /$ RJ17053

Hobbs, R. J., Arico, S., Aronson, J., Baron, J. S., Bridgewater, P., Cramer, V. A., et al. (2006). Novel ecosystems: theoretical and management aspects of the new ecological world order. Glob. Ecol. Biogeogr. 15, 1-7. doi: 10.1111/j.1466-822X.2006.00212.x

Jacob, C., Buffard, A., Pioch, S., and Thorin, S. (2018). Marine ecosystem restoration and biodiversity offset. Ecol. Eng. 120, 585-594. doi: 10.1016/j.ecoleng.2017.09.007
James, A. N., Gaston, K. J., and Balmford, A. (1999). Balancing the Earth's accounts. Nature 401, 323-324. doi: 10.1038/43774

Jellinek, S., Wilson, K. A., Hagger, V., Mumaw, L., Cooke, B., Guerrero, A. M., et al. (2019). Integrating diverse social and ecological motivations to achieve landscape restoration. J. Appl. Ecol. 56, 246-252. doi: 10.1111/1365-2664.13248

Kitney, S., Stanway, A. R., and Ryan, M. M. (2018). Volunteer tourism motivations of the marine conservation cambodia project. Curr. Iss. Tourism 21, 1091-1096. doi: 10.1080/13683500.2016.1269727

Kittinger, J. N., Bambico, T. M., Minton, D., Miller, A., Mejia, M., Kalei, N., et al. (2016). Restoring ecosystems, restoring community: socioeconomic and cultural dimensions of a community-based coral reef restoration project. Reg. Environ. Chang. 16, 301-313. doi: 10.1007/s10113-013-0572-x

Lee, S. Y., Hamilton, S., Barbier, E. B., Primavera, J., and Lewis, R. R. (2019). Better restoration policies are needed to conserve mangrove ecosystems. Nat. Ecol. Evol. 3, 870-872. doi: 10.1038/s41559-019-0861-y

Macreadie, P. I., Ollivier, Q. R., Kelleway, J. J., Serrano, O., Carnell, P. E., Ewers Lewis, C. J., et al. (2017). Carbon sequestration by Australian tidal marshes. Sci. Rep. 7:44071. doi: 10.1038/srep44071

Maron, M., and Louis, W. R. (2018). Does it matter why we do restoration? Volunteers, offset markets and the need for full disclosure. Ecol. Manage. Restor. 19, 73-78. doi: 10.1111/emr.12330

McCarthy, D. P., Donald, P. F., Scharlemann, J. P. W., Buchanan, G. M., Balmford, A., Green, J. M. H., et al. (2012). Financial costs of meeting global biodiversity conservation targets: current spending and unmet needs. Science 338, 946-949. doi: 10.1126/science. 1229803

McCarthy, M. A., and Possingham, H. P. (2007). Active adaptive management for conservation. Conserv. Biol. 21, 956-963. doi: 10.1111/j.1523-1739.2007.00677.x

McDonald, T., Gann, G., Jonson, J., and Dixon, K. (2016). International Standards for the Practice of Ecological Restoration - Including Principles and Key Concepts. Washington, DC: Society for Ecological Restoration. doi: 10.1111/rec.12359

McLeod, E., Anthony, K. R. N., Mumby, P. J., Maynard, J., Beeden, R., Graham, N. A. J., et al. (2019). The future of resilience-based management in coral reef ecosystems. J. Environ. Manage. 233, 291-301. doi: 10.1016/j.jenvman.2018.11.034

Menz, M. H. M., Dixon, K. W., and Hobbs, R. J. (2013). Hurdles and opportunities for landscape-scale restoration. Science 339, 526-527. doi: $10.1126 /$ science. 1228334

Milner-Gulland, E. J., Fisher, M., Browne, S., Redford, K. H., Spencer, M., and Sutherland, W. J. (2010). Do we need to develop a more relevant conservation literature? Oryx 44, 1-2. doi: 10.1017/S00306053099 91001

Nilsson, D., Gramotnev, G., Baxter, G., Butler, J. R. A., Wich, S. A., and McAlpine, C. A. (2016). Community motivations to engage in conservation behavior to conserve the Sumatran orangutan. Conserv. Biol. 30, 816-826. doi: $10.1111 /$ cobi. 12650

Orth, R. J., Harwell, M. C., Bailey, E. M., Bartholomew, A., Jawad, J. T., Lombana, A. V., et al. (2000). A review of issues in seagrass seed dormancy and germination: Implications for conservation and restoration. Mar. Ecol. Prog. Ser. 200, 277-288. doi: 10.3354/meps200277

Paling, E., Fonseca, M. S., van Katwijk, M. M., and van Keulen, M. (2009). “Seagrass restoration," in CoastalWetlands: An Integrated Ecosystems Approach, eds G. Perillo, E. Wolanski, D. Cahoon, and C. Hopkinson (Amsterdam), 687-713.

Pandolfi, J. M., Bradbury, R. H., Sala, E., Hughes, T. P., Bjorndal, K. A., Cooke, R. G., et al. (2003). Global trajectories of the long-term decline of coral reef ecosystems. Science 301, 955-958. doi: 10.1126/science.1085706

Perrow, M., and Davy, A. (2002). Handbook of Ecological Restoration. Cambridge: Cambridge University Press. doi: 10.1017/CBO9780511549984

Possingham, H. P., Bode, M., and Klein, C. J. (2015). Optimal conservation outcomes require both restoration and protection. PLoS. Biol. 13:e1002052. doi: 10.1371/journal.pbio.1002052

Primavera, J. H., and Esteban, J. M. A. (2008). A review of mangrove rehabilitation in the Philippines: successes, failures and future prospects. Wetl. Ecol. Manag. 16, 345-358. doi: 10.1007/s11273-008-9101-y

Reguero, B. G., Beck, M. W., Agostini, V. N., Kramer, P., and Hancock, B. (2018). Coral reefs for coastal protection: a new methodological approach and engineering case study in Grenada. J. Environ. Manage. 210, 146-161 doi: 10.1016/j.jenvman.2018.01.024 
Ruiz-Jaen, M. C., and Mitchell Aide, T. (2005). Restoration success: how is it being measured? Restor. Ecol. 13, 569-577. doi: 10.1111/j.1526-100X.2005.00072.x

SER (2004). The SER Primer on Ecological Restoration. Tucson, Arizona.

Sunderland, T., Sunderland-Groves, J., Shanley, P., and Campbell, B. (2009). Bridging the gap: How can information access and exchange between conservation biologists and field practitioners be improved for better conservation outcomes? Biotropica 41, 549-554. doi: 10.1111/j.1744-7429.2009.00557.x

The World Bank (2014). World Development Indicators. Washington, DC: The World Bank.

UNEP (2006). Marine and Coastal Ecosystems and Human Wellbeing: A Synthesis Report Based on the Findings of the Millennium Ecosystem Assessment. 76.

UNEP (2019). New UN Decade on Ecosystem Restoration offers Unparalleled Opportunity for Job Creation, Food Security and Addressing Climate Change. Available online at: https:/www.unenvironment.org/news-and-stories/ press-release/new-un-decade-ecosystem-restoration-offers-unparalleledopportunity

Valiela, I., Bowen, J. L., and York, J. K. (2001). Mangrove forests: one of the world's threatened major tropical environments. Bioscience 51, 807-815. doi: 10.1641/ 0006-3568(2001)051[0807:MFOOTW]2.0.CO;2

van Katwijk, M. M., Thorhaug, A., Marbà, N., Orth, R. J., Duarte, C. M., Kendrick, G. A., et al. (2016). Global analysis of seagrass restoration: the importance of large-scale planting. J. Appl. Ecol. 53, 567-578. doi: 10.1111/1365-2664.12562

Vargas-Hernández, J. G., and Zdunek-Wielgołaska, J. (2020). Urban green infrastructure as a tool for controlling the resilience of urban sprawl. Environ. Dev. Sustain. doi: 10.1007/s10668-020-00623-2

Waltham, N. J., Elliott, M., Lee, S. Y., Lovelock, C., Duarte, C. M., Buelow, C., et al. (2020). UN decade on ecosystem restoration 2021-2030-what chance for success in restoring coastal ecosystems? Front. Marine Sci. 7:71 doi: $10.3389 /$ fmars.2020.00071

Worthington, T., Andradi-Brown, D., Bhargava, R., Buelow, C., Bunting, P., Duncan, C. et al. (2020). Harnessing big data to support the conservation and rehabilitation of mangrove forests globally. One Earth 2, 429-443. doi: 10.1016/j.oneear.2020.04.018

Wortley, L., Hero, J.-M., and Howes, M. (2013). Evaluating ecological restoration success: a review of the literature. Restor. Ecol. 21, 537-543. doi: $10.1111 /$ rec. 12028

Wyborn, C., Jellinek, S., and Cooke, B. (2012). Negotiating multiple motivations in the science and practice of ecological restoration. Ecol. Manage. Restor. 13, 249-253. doi: 10.1111/j.1442-8903.2012.00667.x

Zhang, Y., Cioffi, W., Cope, R., Daleo, P., Heywood, E., Hoyt, C., et al. (2018). A global synthesis reveals gaps in coastal habitat restoration research. Sustainability 10:1040. doi: 10.3390/su1004 1040

Conflict of Interest: The authors declare that the research was conducted in the absence of any commercial or financial relationships that could be construed as a potential conflict of interest.

Copyright (๐ 2020 Bayraktarov, Brisbane, Hagger, Smith, Wilson, Lovelock, Gillies, Steven and Saunders. This is an open-access article distributed under the terms of the Creative Commons Attribution License (CC BY). The use, distribution or reproduction in other forums is permitted, provided the original author(s) and the copyright owner(s) are credited and that the original publication in this journal is cited, in accordance with accepted academic practice. No use, distribution or reproduction is permitted which does not comply with these terms. 